\title{
Achieving High Time-Resolution with a New Flow-through Type Analyzer for Total Inorganic Carbon in Seawater
}

\author{
Hideshi Kimoto, ${ }^{* 1 \dagger}$ Ken Nozaki, ${ }^{* 2}$ Setsuko Kudo, ${ }^{* 3}$ Ken Kato, ${ }^{* 2}$ Akira Negishi, $* 2$ \\ and Hajime KAYANNE*3,*4 \\ *1 Kimoto Electric Co., Ltd., Funahashi, Tennoji, Osaka 543-0024, Japan \\ *2 Energy Electronics Institute, National Institutes of Advanced Industrial Science and Technology, \\ AIST Tsukuba Central 2, Umezono, Tsukuba 305-8568, Japan \\ *3 Japan Science and Technology Corporation, Department of Earth and Planetary Science, \\ The University of Tokyo, Hongo, Bunkyo, Tokyo 113-0033, Japan \\ *4 Department of Earth and Planetary Science, The University of Tokyo, \\ Hongo, Bunkyo, Tokyo 113-0033, Japan
}

\begin{abstract}
A fully automated, continuous-flow-through type analyzer was developed to observe rapid changes in the concentration of total inorganic carbon $\left(C_{\mathrm{T}}\right)$ in coastal zones. Seawater and an $\mathrm{H}_{3} \mathrm{PO}_{4}$ solution were fed into the analyzer's mixing coil by two high-precision valveless piston pumps. The $\mathrm{CO}_{2}$ was stripped from the seawater and moved into a carrier gas, using a newly developed continuous-flow-through $\mathrm{CO}_{2}$ extractor. A mass flow controller was used to assure a precise flow rate of the carrier gas. The $\mathrm{CO}_{2}$ concentration was then determined with a nondispersive infrared gas analyzer. This analyzer achieved a time-resolution of as good as $1 \mathrm{~min}$. In field experiments on a shallow reef flat of Shiraho (Ishigaki Island, Southwest Japan), the analyzer detected short-term, yet extreme, variations in $C_{\mathrm{T}}$ which manual sampling missed. Analytical values obtained by the analyzer on the boat were compared with those determined by potentiometric titration with a closed cell in a laboratory: $C_{\mathrm{T}}$ (flow-through $)=0.980 \cdot C_{\mathrm{T}}$ (titration $)+38.8$ with $r^{2}=0.995(n=34$; September 1998) .
\end{abstract}

(Received October 1, 2001; Accepted December 10, 2001)

\section{Introduction}

Extensive effort has been put into elucidating the role of the ocean in the global carbon cycle, especially its ability to absorb the increased amounts of anthropogenic carbon dioxide being released into the atmosphere. Most of the research and many surveys have been focused on the open sea, ${ }^{1}$ however, the role of coastal zones in the carbon cycle is also of current interest. ${ }^{2,3}$

However, it has been difficult to continuously measure the partial pressure of $\mathrm{CO}_{2}\left(p \mathrm{CO}_{2}\right)$ and the carbonate system in coastal zones where shallow waters impede access by large research ships. Compared with the open sea, these zones, which include coral reefs, have a high primary production per unit and have more complex oceanographic conditions. Therefore, more rapid temporal changes take place in the $\mathrm{CO}_{2}$ system in these coastal zones. For example, the value of $p \mathrm{CO}_{2}$ changed by as much as $50 \mathrm{ppm}$ within $10 \mathrm{~min}$ accompanied with high biological production and tidal currents on a coral reef flat. ${ }^{4}$ These changes in $p \mathrm{CO}_{2}$ suggest correspondingly rapid changes in $C_{\mathrm{T}}$ and total alkalinity $\left(A_{\mathrm{T}}\right)$.

Upon entering the state of solution, $\mathrm{CO}_{2}$ reaches equilibrium with the two ionic species, $\mathrm{HCO}_{3}{ }^{-}$and $\mathrm{CO}_{3}{ }^{2-}$. The four measurable $\mathrm{CO}_{2}$ related parameters are: $\mathrm{pH}, A_{\mathrm{T}}, C_{\mathrm{T}}$, and $p \mathrm{CO}_{2}$. For the analysis of $C_{\mathrm{T}}$ in seawater, the $\mathrm{CO}_{2}$ extracted from a seawater sample by acidification is determined by gas chromatography ${ }^{5,6}$ or coulometric titration, ${ }^{7}$ or with an infrared

\footnotetext{
† To whom correspondence should be addressed.

E-mail: hkimoto@kimoto-electric.co.jp
}

analyzer. ${ }^{8,9}$ In the direct potentiometric titration of seawater, ${ }^{10-15}$ both $C_{\mathrm{T}}$ and $A_{\mathrm{T}}$ can be simultaneously determined by a single titration. The coulometric titration by the SOMMA (single operator multimetabolic analyzer) is acknowledged as the most accurate and precise method. ${ }^{16,17}$ The flowing system previously developed automatically acidifies and strips the $\mathrm{CO}_{2}$ out of a seawater sample, and determines the concentration by integrating the infrared absorbance. ${ }^{18}$ However, an analysis time for one sample, of more than several minutes, is most likely required for the $\mathrm{CO}_{2}$ extraction and other processes which are conducted between batches.

In this paper, a flow-through type analyzer for $C_{\mathrm{T}}$ in seawater is described along with results that demonstrate continuous, high time-resolution measurement of $C_{\mathrm{T}}$ on a coral reef flat. The continuous flow-through $\mathrm{CO}_{2}$ extractor ${ }^{19}$ developed in this research project permitted the most effective extraction of $\mathrm{CO}_{2}$ from an acidified sample to date. The $\mathrm{CO}_{2}$ concentration was measured with a nondispersive infrared gas analyzer (NDIR). A high-precision valveless piston pump was used for seawater sampling and a mass flow controller (MFC) was used to assure a precise flow rate of carrier gas. Errors caused by drifting were periodically compensated for with two $C_{\mathrm{T}}$ standard solutions of different concentrations.

\section{Experimental}

\section{Instrumentation}

The main components used in the construction of the fully automated, continuous-flow-through $C_{\mathrm{T}}$ analyzer were: two 


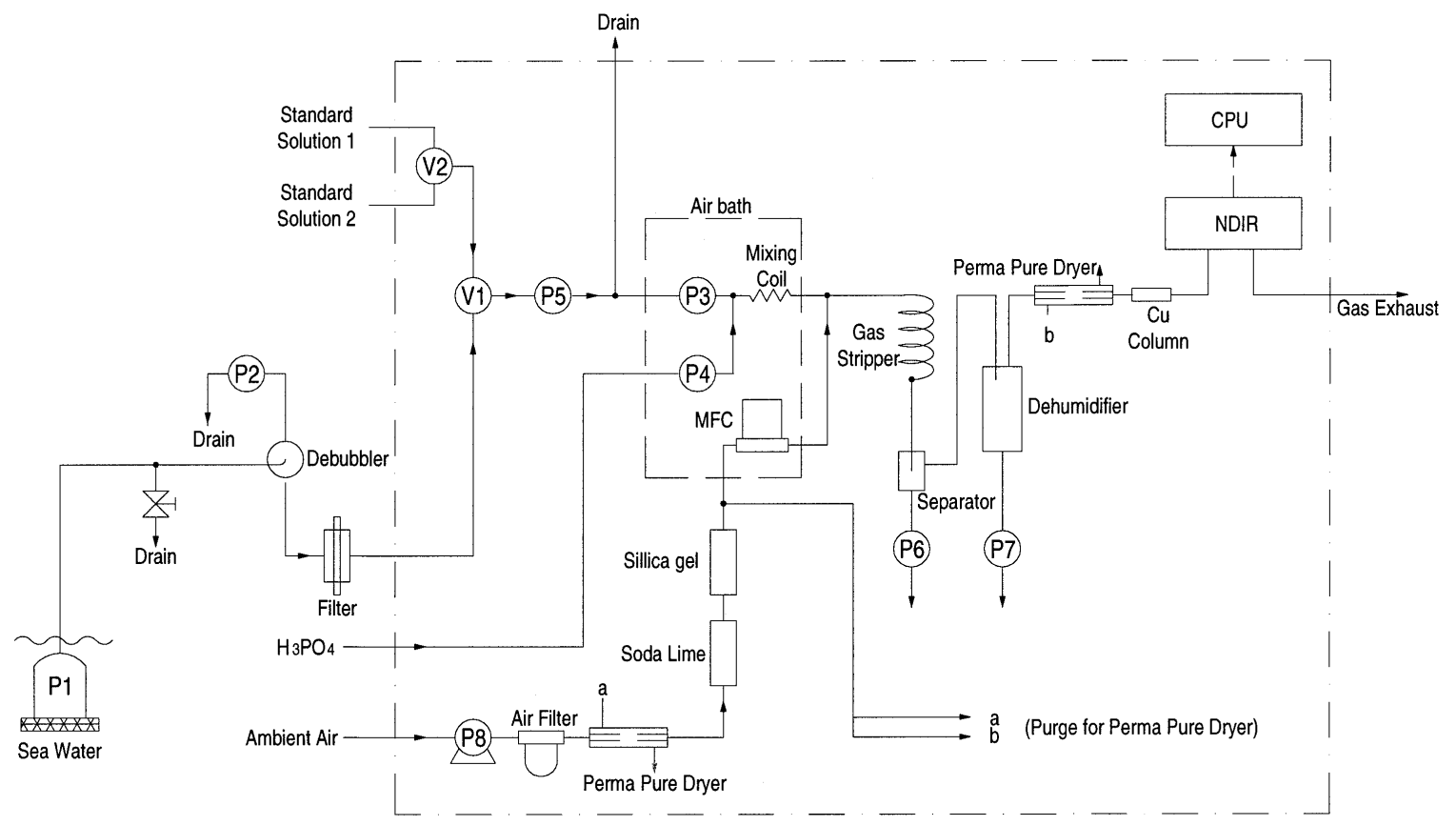

Fig. 1 Schematic diagram of the fully automated, continuous-flow-through type $C_{\mathrm{T}}$ analyzer. P1, underwater pump; P3 and P4, valveless piston pumps; P2, P5, P6 and P7, peristaltic tube pumps; V1 and V2, valves; MFC, mass flow controller.

valveless piston pumps (P3, P4; quantitative pumps, with a $0.1 \%$ precision; pulse motor driven; RH-00CKC-LF, Fluid Metering Inc., USA), a mixing coil (PTFE tube; i.d. $=1 \mathrm{~mm}, \mathrm{~L}$ $=500 \mathrm{~mm}$ ), the flow-through $\mathrm{CO}_{2}$ extraction unit, an NDIR (LI6252, LI-COR, USA), and a microcomputer to control the entire system. The schematic diagram is shown in Fig. 1.

Seawater was fed by an underwater pump (P1; 3-TM, Tsurumi Manufacturing Co., Ltd., Japan) to the analyzer which was mounted on a small research motorboat (the "Crest"). The underwater pump, made of Ti and plastic, was hung from the boat into the sea. Whenever the pump is activated, a portion of seawater is fed into an approx. $1.5 \mathrm{~cm}^{3}$ glass debubbler, at which point the main sampling line branches into two paths. Bubbles are removed from the seawater sample by a pump (P2; peristaltic pump, flow rate: approx. $20 \mathrm{~cm}^{3} \mathrm{~min}^{-1}$; pump head: P-07017-20, Masterflex, USA). The amount of seawater required for analysis goes toward a second pump (P5; peristaltic pump, flow rate: approx. $5 \mathrm{~cm}^{3} \mathrm{~min}^{-1}$; pump head: P-07014-20, Masterflex, USA) through a filter (47 $\mathrm{mm} \phi$; GF/F, Whatman, UK). The head of the seawater overflow drain was positioned $30 \mathrm{~cm}$ higher than P3 in order to keep the pressure at the inlet of P3 constant. P3 was set at a flow rate of $2 \mathrm{~cm}^{3} \mathrm{~min}^{-1}$. The seawater from P3 mixes with a $0.5 \mathrm{~mol} \mathrm{dm}^{-3} \mathrm{H}_{3} \mathrm{PO}_{4}$ solution, which is supplied by $\mathrm{P} 4$ at a flow rate of $0.3 \mathrm{~cm}^{3} \mathrm{~min}^{-1}$. The mixed solution then moves to a gas stripper (continuous-flowthrough $\mathrm{CO}_{2}$ extractor) ${ }^{19}$ with $\mathrm{CO}_{2}$-free dried air as the carrier gas, at a flow rate of $200 \mathrm{~cm}^{3} \mathrm{~min}^{-1}$, controlled precisely by the MFC (FC-260E, AERA Japan Ltd., Japan). Thus, $\mathrm{CO}_{2}$ is stripped out of the seawater sample. The precision of P3 and the MFC directly affect quantification, so the temperature was kept at 25 or $28^{\circ} \mathrm{C}$ in the field depending on the seasonal temperatures and $20^{\circ} \mathrm{C}$ in the laboratory, 2 to $3^{\circ} \mathrm{C}$ lower than their surroundings. This was done to control the drift of flow rates due to temperature variation, with an aim of a $0.1 \%$ flow rate drift per hour. As shown in Fig. 2, the gas stripper consists of a spiral Teflon ${ }^{\circledR}$ tube wound around a pipe of $48 \mathrm{~mm}$ outside diameter. Care was taken to keep the stream moving down the tube. The optimal conditions for the stripper were a PFA tube with $1.6 \mathrm{~mm}$ inside diameter and $2 \mathrm{~m}$ length. The gas separated from the liquid is passed through a dehumidifier (Peltier element cooler; DH-10, Komatsu Electronics Inc., Japan) and then a Perma Pure Dryer ${ }^{\circledR}$ (Gas sample Nafion ${ }^{\circledR}$ dryer, $1.8 \mathrm{~m}$; PD-750, Perma Pure Inc., USA) to assure the drying of the carrier gas containing $\mathrm{CO}_{2}$. The gas is next passed through a $\mathrm{Cu}$ column as a halogen gas trap, and then the $\mathrm{CO}_{2}$ concentration is measured at $1 \mathrm{~s}$ intervals by the NDIR. P6 and P7 in Fig. 1 indicate drain pumps (Pump head: P-07016-20, Masterflex, USA) that remove water from the separator and dehumidifier.

The system was controlled by an industrial computer (IPCBx/M400 (PC), Contec Co., Ltd., Japan) with data acquisition and control software written in Borland $\mathrm{C}++$ Builder (Borland Software Corp., USA). The NDIR was controlled via serial communication, and the valves and the pumps were controlled with a digital relay board (IBX-2724C, Interface Corp., Japan).

\section{Reagents}

Sodium carbonate for volumetric analysis (99.97\% purity) was purchased from Asahi Glass Co., Ltd., Japan. By diluting 5 mol dm ${ }^{-3} \mathrm{HCl}$ (for volumetric analysis, Wako Pure Chemical Industries Ltd., Japan), we obtained a solution of $0.2 \mathrm{~mol} \mathrm{\textrm {kg } ^ { - 1 }}$ $\mathrm{HCl}$ for use as a titrant for potentiometric titration. The concentration of the $\mathrm{HCl}$ solution was determined by titrating with a standardized $\mathrm{AgNO}_{3}$ solution on a balance, using a micropump. The purity of $\mathrm{AgNO}_{3}$ was 99.9\%. Unless otherwise specified, all materials were analytical-reagent grade. All solutions were prepared with deionized water from a MilliQ system.

\section{$C_{T}$ standard solutions}

Two types of standard solution, (Solution 1) $\mathrm{NaHCO}_{3}$ and (Solution 2) a mixture of $\mathrm{Na}_{2} \mathrm{CO}_{3}$ and $\mathrm{HCl}$, each containing 0.7 mol kg-1 $\mathrm{NaCl}$, were used in order to compensate for the drift 


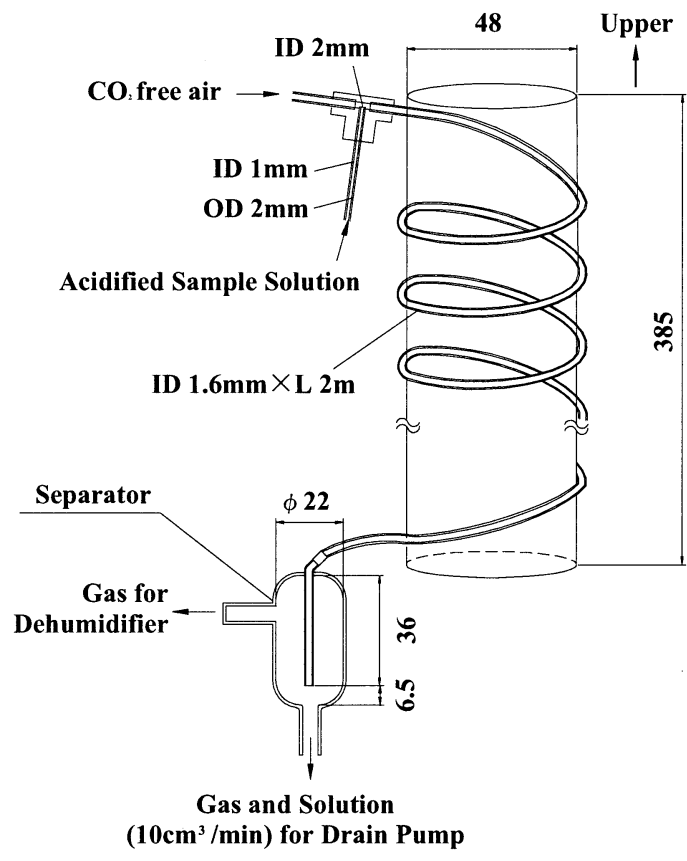

Fig. 2 Detail of the flow-through type $\mathrm{CO}_{2}$ gas stripper, which consists of a spiral tube wound around a pipe.

and variation in sensitivity. Prior to the preparation of the solutions, deionized water was degassed by heating or keeping under reduced pressure. The $C_{\mathrm{T}}$ concentrations were determined by coulometry and/or potentiometric titration, using a precision $A_{\mathrm{T}}$ and $C_{\mathrm{T}}$ analyzer (EN-501A, Kimoto Electric Co., Ltd., Japan), which is described below.

Approximate $1900 \mathrm{~cm}^{3}$ of each of the standard solutions was placed into a $2000 \mathrm{~cm}^{3}$ reinforced oblong bag with an interior made of polyethylene and an exterior made of nylon-6 (Nihon Kimu Co., Ltd., Japan). The bag was equipped with two ports, one of which was used solely to remove air bubbles. The headspace was thus reduced to a negligible volume compared with the solution volume. The solutions were supplied into the lines of the $C_{\mathrm{T}}$ analyzer through a Tygon ${ }^{\circledR}$ tube with $1.6 \mathrm{~mm}$ inside diameter.

\section{Calibration}

To avoid errors caused by the pumps (especially P3), the MFC, the gas stripper and the NDIR, two standard solutions of different concentrations, (e.g. 1745 and $\left.2368 \mu \mathrm{mol} \mathrm{kg}{ }^{-1} C_{\mathrm{T}}\right)$ were periodically supplied through valves V1 and V2 (see Fig. 1) to calibrate the analyzer. It was expected that the $C_{\mathrm{T}}$ values for samples would fall between the two standard values. Typically, the standard solutions were supplied for $6 \mathrm{~min}$ each, every $2 \mathrm{~h}$ between measurement intervals.

In the experiments to estimate the efficiency of $\mathrm{CO}_{2}$ stripping from samples, the NDIR was calibrated with a standard gas (480 ppm $\mathrm{CO}_{2}$ balanced with air; Takachiho Chemical Industrial Co., Ltd., Japan). The flow rate of the MFC was also calibrated with a digital bubbler meter (SF-1100, STEC Inc., Japan).

\section{Other instruments}

In contrast to the flow-through type analyzer, the fully automated precision $A_{\mathrm{T}}$ and $C_{\mathrm{T}}$ analyzer consists of eight main components: a sample pipette (approx. $100 \mathrm{~cm}^{3}$ ), a closed cell for titration, an automatic piston burette, a $\mathrm{pH}$ meter (high input impedance digital voltmeter, readable to $0.1 \mathrm{mV}$ ) a cell for $\mathrm{CO}_{2}$ generation from acidified seawater, a coulometer (CM5012, UIC Inc., USA), the NDIR (Ir1520, Servomex, UK), and a microcomputer. In principle, the closed cell is based on that in the DOE Handbook, ${ }^{1}$ thus, $A_{\mathrm{T}}$ and $C_{\mathrm{T}}$ can be simultaneously determined by a single titration. It takes 20 and $45 \mathrm{~min}$, from sampling to cleaning the cells, for potentiometric titration and coulometry respectively. Therefore, the former method was mainly used in order to finish analyzing many samples during the limited survey term. This analyzer was calibrated with $\mathrm{Na}_{2} \mathrm{CO}_{3}$ standard solutions. ${ }^{16}$ Under optimum conditions, the precision $\left(\sigma_{n-1}\right)$ for $C_{\mathrm{T}}$ analyses by both coulometry and potentimetric titration was within $2 \mu \mathrm{mol} \mathrm{kg} \mathrm{kg}^{-1}(n=10)$ for 1800 - $2000 \mu \mathrm{mol} \mathrm{kg}{ }^{-1} C_{\mathrm{T}}$ solutions. The accuracy of the methods was estimated to be approx. $2 \mu \mathrm{mol} \mathrm{kg}{ }^{-1}$ in this research.

Salinity was measured with a Portasal salinometer (8410A, Guildline Instruments Ltd., USA).

\section{Manual water samplings}

For laboratory analysis of $C_{\mathrm{T}}$ with the aforementioned precision analyzer, each sample was put into a $1 \mathrm{~L}$ Duran bottle, leaving a headspace of less than $1 \%$ of the bottle volume, and poisoned by the addition of $1 \mathrm{~mL}$ of a saturated $\mathrm{HgCl}_{2}$ solution in order to prevent bacterial activity. In addition, the samples were stored in the dark until analysis. In the survey done in September 1998, the samples had no $\mathrm{HgCl}_{2}$ added and, pending analysis within $24 \mathrm{~h}$ after collection, were stored, in the dark, at $4-10^{\circ} \mathrm{C}$. A $250 \mathrm{~mL}$ sample was collected to measure the salinity. The samples for the measurements of $C_{\mathrm{T}}$ and salinity were collected at approx. $1-2 \mathrm{~h}$ intervals for $2-3 \mathrm{~d}$ during each survey.

\section{Results and Discussion}

\section{Laboratory studies}

$\mathrm{CO}_{2}$ gas stripper. The liquid containing $\mathrm{CO}_{2}$, at an initial concentration of $C_{\mathrm{T}}(0)$, is first introduced into the $\mathrm{CO}_{2}$ gas stripper (Fig. 2) of the flow-through type $C_{\mathrm{T}}$ analyzer, by a carrier gas at a given flow rate. When the liquid has passed through a stripping tube of length $L$ and reaches its outlet, the partial pressure of $\mathrm{CO}_{2}$ in the carrier gas is given as $p \mathrm{CO}_{2}{ }^{\mathrm{g}}(L)$ and the concentration of $\mathrm{CO}_{2}$ remaining in the liquid is given as $C_{\mathrm{T}}(L)$. Let us suppose $p \mathrm{CO}_{2}$ in the gas and $C_{\mathrm{T}}$ in the liquid is at an arbitrary distance $x$ from the inlet. If the differential of $p \mathrm{CO}_{2}{ }^{\mathrm{g}}(x)$ is proportional to $C_{\mathrm{T}}(x)$ and the differential of $x$ at a constant flow rate, we can express it as

$$
\mathrm{d}\left(p \mathrm{CO}_{2}{ }^{\mathrm{g}}(x)\right)=a_{1} \cdot C_{\mathrm{T}}(x) \mathrm{d} x
$$

where $a_{1}$ is constant. Since the initial number of moles of $\mathrm{CO}_{2}$ passing the inlet in a unit of time is equal to the sum of the number of moles of $\mathrm{CO}_{2}$ in the gas and in the liquid at any distance of $x$ from the inlet, we obtain:

$$
C_{\mathrm{T}}(x)=C_{\mathrm{T}}(0)-b \cdot p \mathrm{CO}_{2}{ }^{\mathrm{g}}(x)
$$

where $b=V / \rho v R T, \rho$ is the density $\left(\mathrm{kg} \mathrm{dm}^{-3}\right)$ of the seawater sample, $v$ is the flow rate $\left(\mathrm{cm}^{3} \mathrm{~min}^{-1}\right)$ of the sample, $V$ is the flow rate $\left(\mathrm{cm}^{3} \mathrm{~min}^{-1}\right)$ of the carrier gas, $R$ is the gas constant $\left(0.08205 \mathrm{dm}^{3}\right.$ atm $\left.\mathrm{K}^{-1} \mathrm{~mol}^{-1}\right)$, and $T$ is the temperature on the Kelvin scale. Using Eqs. (1) and (2), we obtain the following relationships: 


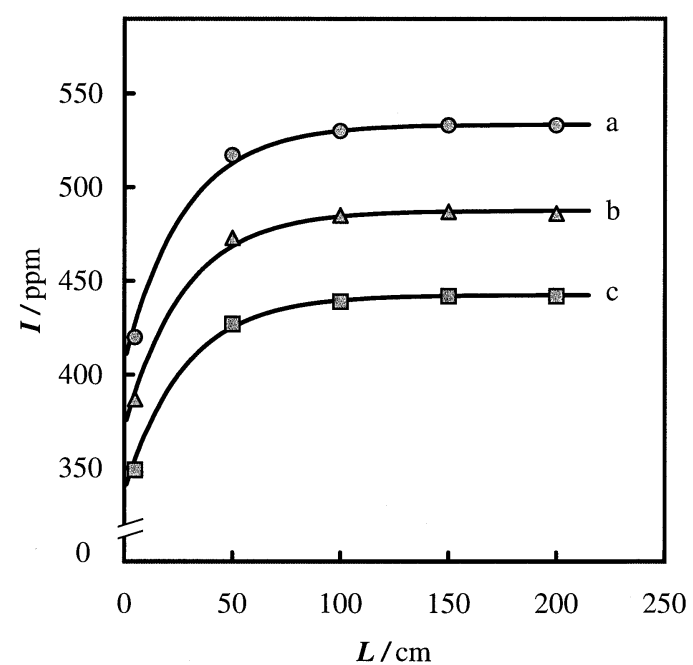

Fig. 3 Effect of stripping tube length $(L)$ on NDIR signal intensity (I). $C_{\mathrm{T}}(\mu \mathrm{mol} \mathrm{kg}-1)$ : (a) 2480, (b) 2250, (c) 2030. Plots of $I$ against $L$ were obtained experimentally. The three curves were drawn by using $p \mathrm{CO}_{2}{ }^{\mathrm{g}}(L)$ values calculated by substituting the values $k=0.0362 \mathrm{~cm}^{-1}$ and $d=39.7 \mathrm{~cm}$ into Eq. (3b).

$$
\begin{aligned}
& \ln \left(\frac{p \mathrm{CO}_{2}{ }^{\mathrm{g}}(\infty)-p \mathrm{CO}_{2}^{\mathrm{g}}(x)}{p \mathrm{CO}_{2}{ }^{\mathrm{g}}(\infty)}\right)=-k x \\
& p \mathrm{CO}_{2}{ }^{\mathrm{g}}(x)=a(\rho v R T / V) C_{\mathrm{T}}(0)
\end{aligned}
$$

where $a=1-\exp (-k x), k$ is constant and $C_{\mathrm{T}}$ approaches 0 as $x \rightarrow \infty$.

Figure 3 shows the effect of stripping tube length, $L$, on the NDIR signal intensity, indicating that $a$ approaches unity at $L \geqq$ $150 \mathrm{~cm}$; thus, $p \mathrm{CO}_{2}$ at $x \rightarrow \infty$ can be experimentally obtained. As given in Fig. 4, Eq. (3a) was plotted by use of the values of $p \mathrm{CO}_{2}{ }^{\mathrm{g}}(x)$ on the ppm scale from Fig. 3 and the relation of $x=L$. A linear regression for experimental plots of $\ln \left[\left(p \mathrm{CO}_{2}{ }^{\mathrm{g}}(\infty)-\right.\right.$ $\left.\left.p \mathrm{CO}_{2}{ }^{\mathrm{g}}(L)\right) / p \mathrm{CO}_{2}{ }^{\mathrm{g}}(\infty)\right] \quad(=y)$ vs. $L$ yielded the following relationship: $y=-0.0362 L-1.476$ with $r^{2}=0.997$. This indicates that the above model was experimentally valid when the stripping tube lengths were not longer than $150 \mathrm{~cm}$, at the least. This experimental equation gave an intercept of -1.476 , which suggests that $\mathrm{CO}_{2}$ was stripped into gas, to some extent, as soon as the liquid containing $\mathrm{CO}_{2}$ was introduced into the stripper by the carrier gas. When $x=L+d$, Eq. (3a) becomes

$$
\ln \left(\frac{p \mathrm{CO}_{2}^{\mathrm{g}}(\infty)-p \mathrm{CO}_{2}^{\mathrm{g}}(x)}{p \mathrm{CO}_{2}{ }^{\mathrm{g}}(\infty)}\right)=-k(L+d)
$$

where $L(\mathrm{~cm})$ is the length of the stripper; the following values were obtained: $k=0.0362 \mathrm{~cm}^{-1}$ and $d=39.7 \mathrm{~cm}$. In Fig. 3, we drew three curves by using the $p \mathrm{CO}_{2}{ }^{\mathrm{g}}(x)$ values that were calculated by substituting these $k$ and $d$ values into Eq. (3b). The curves passed through the experimental plots, demonstrating that the theoretical values were valid. The plots were not corrected for the efficiency of $\mathrm{CO}_{2}$ stripped from samples, $s=\left(C_{\mathrm{T}}(0)-C_{\mathrm{T}}(L)\right) / C_{\mathrm{T}}(0)$. Figure 4 indicates that the value of $a$ in Eq. (4) approaches unity at $L \geqq 150 \mathrm{~cm}$ and $p \mathrm{CO}_{2}$ at $x \rightarrow \infty$ can be experimentally determined. A stripper of 200 $\mathrm{cm}$ in length was used for the analyzer mounted on the "Crest" boat. In this case, $a=1-\exp (-k(L+d))=0.999$, so we conclude that $\mathrm{CO}_{2}$ was stripped almost completely into gas.

By using the standard solution with $C_{\mathrm{T}}=1700 \mu \mathrm{mol} \mathrm{kg}^{-1}$ and Eq. (4), we calculated that $98.1 \pm 3.0 \%$ of the $\mathrm{CO}_{2}$ was stripped.

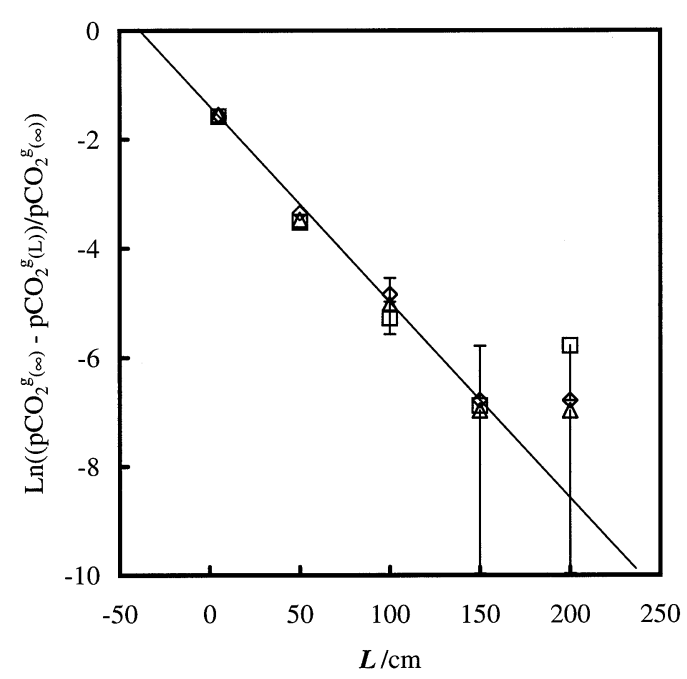

Fig. 4 Plots of $\ln \left[\left(p \mathrm{CO}_{2}{ }^{\mathrm{g}}(\infty)-p \mathrm{CO}_{2}{ }^{\mathrm{g}}(L)\right) / p \mathrm{CO}_{2}{ }^{\mathrm{g}}(\infty)\right]$ against stripping tube length $(L)$. Equation (3a) is plotted by use of $p \mathrm{CO}_{2}{ }^{\mathrm{g}}(\infty)$ values obtained from Fig. 3 and the relation of $x=L$. In the linear regression, data at $L=200 \mathrm{~cm}$ were not included. $C_{\mathrm{T}}\left(\mu \mathrm{mol} \mathrm{kg}{ }^{-1}\right)$ and

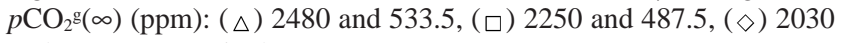
and 442.5 , respectively.

On the other hand, the above $s$ value estimated from the $\mathrm{CO}_{2}$ concentration in liquid waste collected from the stripper outlet, $C_{\mathrm{T}}(L)$, was $99.4 \pm 0.5 \%$. In these experiments, $\mathrm{P} 3, \mathrm{P} 4$, the NDIR and the MFC were all calibrated. The liquid waste was collected and analyzed, taking care not to expose it to air. The $C_{\mathrm{T}}(L) / C_{\mathrm{T}}(0)$ ratio was less than 0.006 , in which $C_{\mathrm{T}}(L)$ was calculated from the fugacity of $\mathrm{CO}_{2}$ in equilibrium with seawater, ${ }^{16}$ so the $\mathrm{CO}_{2}$ distribution in equilibrium between gas and liquid was not considered.

Flow rates of seawater sample and carrier gas, and calibration curve. According to Eq. (4), $p \mathrm{CO}_{2}$ is proportional to $v / V$. It was also experimentally supported: $p \mathrm{CO}_{2}$ was measured for variable $v$ at $V=400 \mathrm{~cm}^{3}$ and variable $V$ at $v=2 \mathrm{~cm}^{3}$ with the approx. $2000 \mu \mathrm{mol} \mathrm{\textrm {kg } ^ { - 1 }} C_{\mathrm{T}}$ solution. A linear regression between NDIR signal intensity $(I)$ and $v / V$ gave an equation of $I$ $=4.223 \cdot 10^{4}(v / V)+5.30$ : its intercept was much smaller than the measured $I$ values. The NDIR signal intensity was found to be proportional to $C_{\mathrm{T}}$, with a correlation of $r^{2}=0.999$.

Response stability and time resolution. In order to clarify the response stability of the analyzer, three standard solutions of different concentrations were analyzed repeatedly, one after another, at $5 \mathrm{~min}$ intervals, for $8 \mathrm{~h}$. The averages of variation for $C_{\mathrm{T}}$ analytical values were $-0.43,-0.33$ and $-0.12 \% \mathrm{~h}^{-1}$ for approx. 1300, 1700 and $2100 \mu \mathrm{mol} \mathrm{kg}^{-1} C_{\mathrm{T}}$ solutions, respectively, where the variations from data for $1 \mathrm{~h}$ were averaged for $8 \mathrm{~h}$. The NDIR signal intensities decreased gradually over time.

The drift of analytical values for an approx. $1700 \mu \mathrm{mol} \mathrm{kg}{ }^{-1}$, $C_{\mathrm{T}}$ solution was compensated for by using analytical values for approx. 1300 and $2100 \mu \mathrm{mol} \mathrm{kg}{ }^{-1} C_{\mathrm{T}}$ solutions at $2 \mathrm{~h}$ intervals. After the compensation, the average variation and the standard deviation $\left(\sigma_{n}\right)$ for the approx. $1700 \mu \mathrm{mol} \mathrm{kg}{ }^{-1} C_{\mathrm{T}}$ solution were $-0.07 \% \mathrm{~h}^{-1}$ and $2.1 \mu \mathrm{mol} \mathrm{kg} \mathrm{kg}^{-1}(n=24)$, respectively. These findings suggest that the correction performed using data from the two standard $C_{\mathrm{T}}$ solutions obtained at $1-2 \mathrm{~h}$ intervals makes it possible to determine $C_{\mathrm{T}}$ with an error of $0.24 \%$ as $2 \sigma_{n}$.

The response to $\mathrm{CO}_{2}$ (Fig. 5) was obtained by enlarging the time scale for a portion of the original raw data. The elapsed 


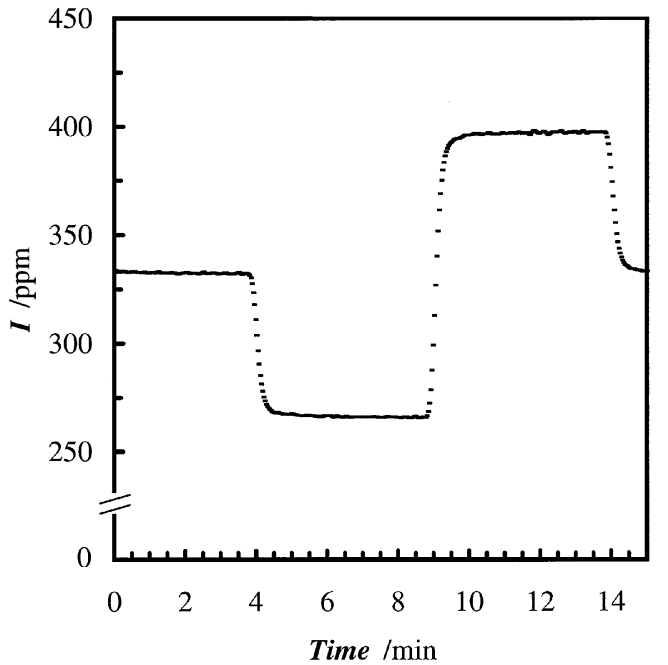

Fig. 5 Response to $\mathrm{CO}_{2}$ of the $C_{\mathrm{T}}$ analyzer. This figure was obtained by enlarging the time scale for a portion of the original raw data. In the raw data, the NDIR signal intensities $(I)$ were measured at $1 \mathrm{~s}$ intervals. $C_{\mathrm{T}}$ standard solutions analyzed (from the left): approx. 1700, 1300 and $2100 \mu \mathrm{mol} \mathrm{kg}{ }^{-1}$.

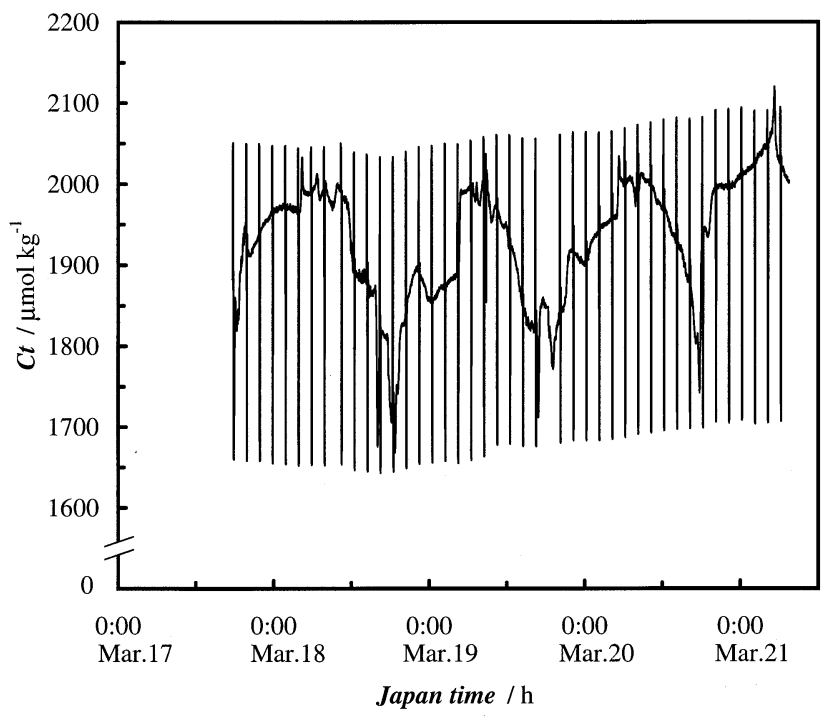

Fig. 6 Raw data obtained without compensation or correction, as measured on a reef flat of Shiraho, Ishigaki Island, Southwest Japan, over approx. 3.5 days from March 17 - 21, 1999. Japan time is universal time plus $9 \mathrm{~h}$. Two standard solutions (1698 and 2049 $\mu \mathrm{mol} \mathrm{kg}^{-1} C_{\mathrm{T}}$ ) were introduced into the $C_{\mathrm{T}}$ analyzer every $2 \mathrm{~h}$, between measurement intervals.

response time at $T(90 \%)$ was $28 \pm 1 \mathrm{~s} . T(90 \%)$ is the point past which a $90 \%$ steady NDIR signal was reached. The median of these data points over a $1 \mathrm{~min}$ interval was used; therefore a time resolution of 1 min was obtained.

\section{Field studies}

The continuous $C_{\mathrm{T}}$ analyzer was tested together with a continuous $A_{\mathrm{T}}$ analyzer, ${ }^{20}$ mounted on the "Crest" boat anchored on a shallow reef flat of Shiraho, ${ }^{21}$ Ishigaki Island, Southwest Japan. The reef crest, when exposed during low tides, separates reef water from the outer ocean, causing it to stagnate. During these stagnant periods, reef water provides ideal, naturallyclosed conditions in which changes in the reef water carbonate
Table 1 Drift for analytical values of $C_{\mathrm{T}}$ standard solutions

\begin{tabular}{ccc}
\hline Date & $C_{\mathrm{T}} / \mu \mathrm{mol} \mathrm{kg} \mathrm{kg}^{-1}$ & Drift $/ \% \mathrm{~h}^{-1}$ \\
\hline Sept. 21 - 23, 1998 & 1745 & 0.51 \\
& 2368 & 0.54 \\
Dec. 3 -5, 1998 & 1564 & 0.18 \\
& 2278 & 0.23 \\
Mar. 18 - 19, 1999 & 1698 & $-0.03,{ }^{\mathrm{a}} 0.08^{\mathrm{b}}$ \\
& 2049 & $-0.04,{ }^{\mathrm{a}} 0.06^{\mathrm{b}}$ \\
Mar. 20 -21, 1999 & 1698 & 0.05 \\
& 2049 & 0.05 \\
\hline
\end{tabular}

a. 0:00 - 18:25, Mar. 18 .

b. 20:25, Mar. 18 - 23:59, Mar. 19.

system are directly related to community metabolism. The analyzers were stored in a plastic box on the boat and were powered by a diesel engine generator. All of the system was designed to be self-regulating except for filter replacement and the supplying of solution at $2 \mathrm{~d}$ intervals. The analyzer was run for three to six days on three occasions: September 1998, December 1998 and March 1999. Averaged data from the NDIR were recorded at $1 \mathrm{~s}$ intervals on a data logger and also at 1 min intervals on a telemeter from the boat by cellular phone.

Response stability. In the field observation, two standard solutions (1698 and $2049 \mu \mathrm{mol} \mathrm{kg} \mathrm{kg}^{-1} C_{\mathrm{T}}$ respectively, in the March observation) were introduced into the $C_{\mathrm{T}}$ analyzer every $2 \mathrm{~h}$, between measurement intervals, to verify stability. Figure 6 illustrates the raw data obtained without compensation or correction, as measured over 3.5 days. Table 1 shows the results of drift for analytical values of $C_{\mathrm{T}}$ standard solutions obtained during the three seasonal observations: September 1998, December 1998 and March 1999. The drift improved with each seasonal survey, because of improvements in the analyzer and operation skill, etc.

Comparing analytical values for the above $C_{\mathrm{T}}$ solutions at $4 \mathrm{~h}$ intervals allowed us to compensate for the drift of the intervening analytical values. After the compensation, the standard deviations $\left(\sigma_{n}\right)$ for the analytical values were obtained as 2.1 and $1.7 \mu \mathrm{mol} \mathrm{kg}^{-1}(n=40)$, respectively, for the 1698 and $2049 \mu \mathrm{mol} \mathrm{kg}^{-1} C_{\mathrm{T}}$ solutions. The response stability was good, in spite of the imperfect conditions: i.e. running the analyzer on a small research boat with the electricity supplied by a diesel engine generator.

Comparison of analysis by the CT analyzer with manual sampling and laboratory analysis. We compared analytical values monitored with seawater from the Shiraho Coral Reef by the flow-through type $C_{\mathrm{T}}$ analyzer with those determined by potentiometric titration with a closed cell in the laboratory (Fig. 7). Samples for the titration were carefully collected by manual water sampling. A rapid change in $C_{\mathrm{T}}$ can be seen: as much as $200 \mu \mathrm{mol} \mathrm{kg} \mathrm{kg}^{-1}$ within approx. $20 \mathrm{~min}$. At the experimental points indicated by black circles, there was a change of approx. $100 \mu \mathrm{mol} \mathrm{kg}-1$ of $C_{\mathrm{T}}$ in just a few minutes. This suggests that inconsistency in sampling time, between automated and manual samplings, probably caused a large error. So, such experimental points are excluded in the following discussion of a correlation between analytical values obtained by the two methods.

In Table 2, analytical values obtained by the $C_{\mathrm{T}}$ analyzer, $C_{\mathrm{T}}$ (flow-through), are compared with those determined by potentiometric titration, $C_{\mathrm{T}}$ (titration). The correlations between $C_{\mathrm{T}}$ (flow-through) and $C_{\mathrm{T}}$ (titration) were best from September 21 - 23, 1998 and worst from March 18 - 19, 1999. Thus, the relationship between $C_{\mathrm{T}}$ (flow-through) and $C_{\mathrm{T}}$ (titration) did not 


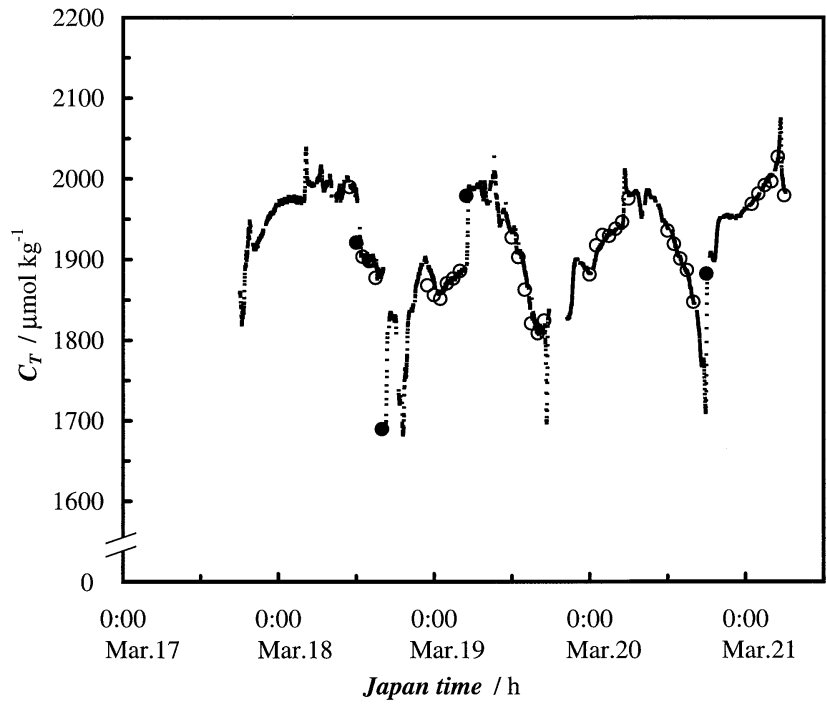

Fig. 7 Variation in $C_{\mathrm{T}}(\cdot)$ measured by the $C_{\mathrm{T}}$ analyzer on a reef flat of Shiraho, over approx. 3.5 days from March 17 - 21, 1999. Analytical values determined by potentiometric titration in the laboratory are also marked by white $(\mathrm{O})$ and black $(\bullet)$ circles. At the experimental points indicated by black circles, there was a change

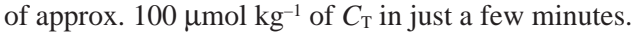

follow the tendency of the drift to improve (see Table 1). From March 18 - 19, waves caused by the prevailing SSW wind rocked the "Crest" boat from side to side; the lowest correlation coefficient can be accounted for by this rocking of the boat. During this period, short-term changes in $C_{\mathrm{T}}$, probably due to wind effects on the system, were recorded in the continuous data. It is also probable that the wind effect lowered the correlation between analytical values of the seawaters sampled automatically and manually. Consequently, we conclude that automated and continuous measurements by the analyzer can allow data collection with high temporal resolution; such automatic sampling avoids errors from manual sampling on small research boats.

The use of the flow-through type $C_{\mathrm{T}}$ analyzer in the field led to the development of another version which permitted rapid and more precise analysis for laboratory use..$^{22}$ The new version will be described in other paper.

\section{Conclusion}

We have achieved the goal of developing an automated, continuous-flow-through type $C_{\mathrm{T}}$ analyzer that can take measurements with a much higher time-resolution, as good as 1 min, than was previously possible. Thus, it is expected that the newly developed $C_{\mathrm{T}}$ analyzer will be useful for characterizing rapid temporal changes in the $\mathrm{CO}_{2}$ system in coastal zones. The analyzer can be used for moored buoy based measurements.

\section{Acknowledgements}

The development of the flow-through type $C_{\mathrm{T}}$ analyzer and the fieldwork were supported by grants from the "Originative Study Result Fostering Project" and "Core Research for Evolutional Science \& Technology (CREST)", respectively, both of which are funded by the Japan Science and Technology Corporation. We thank Mr. M. Tsuda and Ms. Y. Zhou (Kimoto Electric Co.,
Table 2 Linear regression between analytical values obtained by the continuous $C_{\mathrm{T}}$ analyzer, $C_{\mathrm{T}}$ (flow-through), and those determined by potentiometric titration, $C_{\mathrm{T}}$ (titration), in seawater from the Shiraho Coral Reef, with the equation $C_{\mathrm{T}}$ (flow-through) $=$ $a \cdot C_{\mathrm{T}}($ titration $)+b$

\begin{tabular}{cccrcc}
\hline Date & $\begin{array}{c}C_{\mathrm{T}} / \mu \mathrm{mol} \mathrm{kg} \mathrm{kg}^{-1} \\
\text { range }\end{array}$ & $a$ & $\begin{array}{c}b / \\
\mu \mathrm{mol} \mathrm{kg} \mathrm{kg}^{-1}\end{array}$ & $r^{2}$ & $n$ \\
\hline Sept. 21-23, 1998 & $1665-2091$ & 0.980 & 38.8 & 0.995 & 34 \\
Dec. 3 - 5, 1998 & $1723-2006$ & 1.032 & -58.7 & 0.971 & 18 \\
Mar. 18 - 19, 1999 & $1814-2000$ & 0.924 & 152.9 & 0.894 & 16 \\
Mar. 20-21, 1999 & $1847-2025$ & 1.020 & -39.3 & 0.987 & 18 \\
\hline
\end{tabular}

$r^{2}$ and $n$ denote the square of the correlation coefficient and the number of data points, respectively.

Ltd.) for their work with the $C_{\mathrm{T}}$ analyzer. We are grateful to Mr. T. Kimoto (Res. Inst. Oceano-Chem.), for his valuable advice about accurate analysis of the oceanic carbonate system. Thanks are also due to Mr. W. Suh (Kimoto Electric Co., Ltd.) for operating the precision $A_{\mathrm{T}}$ and $C_{\mathrm{T}}$ analyzer in September 1998, and Mr. H. Hata (CREST2, Jpn. Sci. \& Tech. Corp.), Dr. T. Miyajima (Ocean Res. Inst., Univ. Tokyo), Mr. O. Abe (Atmospheric Hydrospheric Res. Inst., Nagoya Univ.), Mr. Y. Umezawa, and Mr. A. Watanabe (Univ. Tokyo) for their careful seawater sampling. A laboratory on the property of the Yaeyama Station of the Japan Sea-Farming Association in Ishigaki, was kindly offered by the Director, Dr. J. Hirokawa.

\section{References}

1. I. Fung and T. Takahashi, in "The Carbon Cycle", ed. T. M. L. Wigley and D. S. Schimel, 2000, Cambridge University Press, 125.

2. C. M. Duarte and S. Agustí, Science, 1998, 281, 234.

3. M. Frankignoulle, G. Abril, A. Borges, I. Bourge, C. Canon, B. Delille, E. Libert, and J.-M. Théate, Science, 1998, 282, 434.

4. H. Kayanne, A. Suzuki, and H. Saito, Science, 1995, 269, 214.

5. K. Park, G. H. Kennedy, and H. H. Dobson, Anal. Chem., 1964, 36, 1686.

6. R. F. Weiss and H. Craig, Deep-Sea Res., 1973, 20, 291.

7. K. M. Johnson, A. E. King, and J. M. Sieburth, Mar. Chem., 1985, 16, 61.

8. W. S. Broecker and T. Takahashi, J. Geophys. Res., 1966, 71,1575 .

9. C. S. Wong, Deep-Sea Res., 1970, 17, 9.

10. D. Dyrssen and L. G. Sillèn, Tellus, 1967, 19, 113.

11. A. L. Bradshaw, P. G. Brewer, D. K. Shafer, and R. T. Williams, Earth Planet. Sci. Lett., 1981, 55, 99.

12. A. L. Bradshaw and P. G. Brewer, Mar. Chem., 1988, 23, 69.

13. A. L. Bradshaw and P. G. Brewer, Mar. Chem., 1988, 24, 155 .

14. A. G. Dickson, Deep-Sea Res., 1981, 28A, 609.

15. F. J. Millero, J.-Z. Zhang, K. Lee, and D. M. Campbell, Mar. Chem., 1993, 44, 153.

16. DOE, "Handbook of methods for the analysis of the various parameters of the carbon dioxide system in sea water", ed. A. G. Dickson and C. Goyet, 1994, Version 2.1, ORNL/CDIAC-74.

17. K. M. Johnson, K. D. Wills, D. B. Butler, W. K. Johnson, 
and C. S. Wong, Mar. Chem., 1993, 44, 167.

18. D. W. O'Sullivan and F. J. Millero, Mar. Chem., 1998, 60, 75.

19. H. Kimoto, H. Kayanne, K. Nozaki, and S. Kudo, Patent Pending, 1999, JP11-129189.

20. H. Kimoto, H. Kayanne, S. Kudo, K. Nozaki, A. Negishi, and K. Kato, in Abstracts of the IUPAC International Congress on Analytical Sciences 2001, JSAC, Tokyo, 2001, 217 - 218 .
21. H. Kayanne, S. Kudo, H. Hata, K. Nozaki, K. Kato, A. Negishi, H. Saito, F. Akimoto, and H. Kimoto, in Proceedings of the 2nd International Symposium $\mathrm{CO}_{2}$ in the Oceans, Tsukuba, 1999, $407-411$.

22. A. Watanabe, K. Nozaki, K. Kato, A. Negishi, S. Kudo, H. Kimoto, M. Tsuda, and H. Kayanne, in Abstracts of the IUPAC International Congress on Analytical Sciences 2001, JSAC, Tokyo, 2001, 328 - 329. 